\title{
Adherence and Early Initiation of Breastfeeding in Institutional Deliveries - Prospective Observational Cohort Study.
}

\author{
Sandeep $\mathrm{H}^{1}$, Vinod Uplaonkar ${ }^{2}$ \\ ${ }^{1}$ Professor and HOD, Department of Pediatrics, GIMS, Kalaburagi, Karnataka, ${ }^{2}$ Assistant Professor, Department of Pediatrics, KBNIMS, Kalaburagi, Karnataka.
}

\section{Abstract}

Background: Aim: 1. To assess the effect of early initiation of breastfeeding within 1hour on sustain exclusive breastfeeding, 2 . To assess the correct position, attachment and effective suckling in the breastfeeding of infants as practiced by mothers, 3 . To assess the educational background of mother as factor for adherence to breast feeding, 4. Involvement of various healthcare personnel in successful breastfeeding. Subjects and Methods: An observational, prospective cohort study was done at KBNIMS and GIMS Hospital in Kalaburagi from March 2018 to August 2018. Mother-newborn units were observed for mother's and baby's position, attachment and quality assessed by fish bone diagram (Ishikawa). Data thus collected were analysed using Chi-Square test. Results: The results of the study revealed that the highest percentage (47.8\%) of the sample their age were ranged between (18-21) years, (49\%) of them were graduated from primary school and less, (91\%) initiate their breastfeeding during 24 hours in previous baby, In primipara average latch score was 4 and in multipara it was 8 whereas score of 7 in normal vaginal and score of 4 in lscs. Conclusion: Neonatal and infant deaths can be decreased to significant level if breast feeding is initiated within 1 hour. LATCH score is excellent tool for caregivers at all level in hospital. Early initiation will help to sustained and maintain breastfeeding till 6 months of age and avoid top feeding by the mother.

Keywords: Breastfeeding, LATCH Score, Adherence and Early Initiation.

Corresponding Author: Dr Vinod Uplaonkar, Assistant Professor, Department of Pediatrics, KBNIMS, Kalaburagi, Karnataka.

Received: January 2019

Accepted: February 2019

\section{Introduction}

In India, the rates of institutional deliveries are now more than $80 \%$ and number of cesarean sections is increasing at an alarming rate.

The National Family Health Survey 2015-16 (NFHS-4), provides data on Child Feeding Practices and Nutritional Status of Children.Asper data $42.8 \%$ inurban, $41.1 \%$ in rural and totalof $41.6 \%$ (NFHS-3; 23.4\%) Children under age 3 years were breastfed within one hour of birth $(\%)$. Whereas $52.1 \%$ (urban), $55.9 \%$ (rural) and $54.9 \%$ (total) did exclusively breastfed for 6 months. ${ }^{[1]}$

Neonatal mortality has been almost 2.7 million deaths occurring in 2015 (46\% of under 5 child deaths. Analysis of a large cohort of almost 100,000 newborns from three large trials conducted in India, Ghana and Tanzania has shown that the risk of neonatal death was $41 \%$ and $79 \%$ higher among children in whom breastfeeding was initiated between 2-23 hours and 24-96 hours after birth, respectively as compared to infants in whom breastfeeding was initiated within the first hour of life. ${ }^{[2]}$

Breastfeeding has many health benefits for both the mother and infant. Breastfeeding protects against diarrhoea and common childhood illnesses such as pneumonia, and may also have longer-term health benefits, such as reducing the risk of overweight and obesity in childhood and adolescence. Exclusive breastfeeding is recommended up to 6 months of age.

Provision of mother's breast milk to infants within one hour of birth is referred to as "early initiation of breastfeeding" and ensures that the infant receives the colostrum, or "first milk", which is rich in protective factors.

Current evidence indicates that skin-to-skin contact between mother and infant shortly after birth helps to initiate early breastfeeding and increases the likelihood of exclusive breastfeeding for one to four months of life as well as the overall duration of breastfeeding. ${ }^{[3]}$

The rates of cesarean section vary from $11 \%$ to as high as $74 \%$ (1). Cesarean sections are one of the biggest hurdles in initiation of breastfeeding in hospital-born babies. ${ }^{[4]}$ Various studies have shown that infants born by cesarean section are four times less likely to receive breastfeeding within first hour of birth than vaginally delivered infants. ${ }^{[5]}$ Hence, it is logical to make efforts to remove this barrier to early initiation of breastfeeding.

LATCH is a documentation tool for breastfeeding charting and assessment. The LATCH tool was modeled on the Apgar scoring system. A composite score of $0-10$ is possible, depending upon the identified criteria met in each of the key areas of breastfeeding [Table 1]. ${ }^{[6]}$ 
Table 1: Latch score.

\begin{tabular}{|c|c|c|c|}
\hline Assessment & $\mathbf{0}$ & 1 & 2 \\
\hline L Latch H & $\begin{array}{l}\text { Too sleepy } \\
\text { or reluctant }\end{array}$ & Repeated attempts & $\begin{array}{l}\text { Grasps breast } \\
\text { Tongue }\end{array}$ \\
\hline Hold & $\begin{array}{l}\text { No latch } \\
\text { achieved }\end{array}$ & $\begin{array}{l}\begin{array}{l}\text { Hold nipple in } \\
\text { mouth }\end{array} \\
\end{array}$ & $\begin{array}{ll}\text { down } & \text { Lips } \\
\text { flanged }\end{array}$ \\
\hline (Positioning) & & stimulate to suck & Rhythmic sucking \\
\hline A Audible & None & A few with & Spontaneous and \\
\hline \multirow[t]{3}{*}{ swallowing } & & stimulation & $\begin{array}{l}\text { intermittent } \\
\text { Spontaneous }\end{array}$ \\
\hline & & & $\begin{array}{l}\text { and frequent }<24 \\
\text { hours }\end{array}$ \\
\hline & & & old $>24$ hours old \\
\hline T Type of & Inverted & Flat & $\begin{array}{l}\text { Everted (after } \\
\text { stimulation) }\end{array}$ \\
\hline \multicolumn{4}{|l|}{ nipple } \\
\hline C Comfort & Engorged & Filling & Soft \\
\hline (Breast/ & $\begin{array}{l}\text { Cracked, } \\
\text { bleeding, }\end{array}$ & Reddened/small & Tender \\
\hline \multirow[t]{3}{*}{ Nipple) } & $\begin{array}{l}\text { large } \\
\text { blisters, or }\end{array}$ & blisters or bruises & \\
\hline & bruises & & \\
\hline & $\begin{array}{l}\text { Severe } \\
\text { discomfort }\end{array}$ & & \\
\hline H Hold & Full assist & Minimal assist & $\begin{array}{l}\text { No assist from } \\
\text { staff }\end{array}$ \\
\hline \multirow[t]{2}{*}{ (Positioning) } & & & Mother able to \\
\hline & & & $\begin{array}{l}\text { position/hold } \\
\text { infant }\end{array}$ \\
\hline \multicolumn{4}{|c|}{ Total score of 10} \\
\hline \multicolumn{4}{|c|}{ Material and Methods } \\
\hline $\begin{array}{l}\text { An } \\
\text { observational, }\end{array}$ & \multicolumn{3}{|c|}{$\begin{array}{l}\text { prospective cohort study was done at KBNIMS and } \\
\text { GIMS Hospital in }\end{array}$} \\
\hline
\end{tabular}

\section{Subjects and Methods}

Kalaburagi from March 2018 to August 2018.

\section{Inclusion criteria:}

1. Postpartum women who have either normal vaginal delivery or caesarean section with healthy newborn; Normal weight and newborns is rooming in with their mothers.

2. Newborn with LBW.

\section{Exclusion criteria:}

Mothers -highrisk pregnancy, hemodynamicallyunstable (severe PIH).

Neonates -congenital anomalies, prematurity, birth asphyxia, respiratorydistress, encephalopathy or genetic diseases that might affect the study results.

The study was conducted in labour room and post on ward of GIMS and KBNTGH. ANM and GNM assessed the breastfeeding in wards as given in figure (1)

Questionnaire was used as a tool of datacollection to fulfil with objectives of the study which consisted of three parts: including demographic characteristics, reproductive characteristics and LATCH breastfeeding assessment tool is based on observations and descriptions of effective breastfeeding, evaluates five characteristics of breastfeeding. A numerical score $(0,1$ or 2$)$ is assigned to each measure for a possible total score 10, as shown in table (1). Each letter of acronym denotes a category for LATCH

L: represents how well the infant latches onto the breast,

A: represents audible swallowing noted,

T: describes the mother's nipple type,

C: $\quad$ represents the mother's degree of breast or nipple \& general feeding comfort,

$\mathrm{H}$ : evaluates the amount of help the mother needs to position her baby at breast

The Institute Ethics Committee (IEC) approved the study and granted a waiver of individual consent. The study did not involve any alteration in investigations or treatment of any patient.

Data are analyzed through the use of Excel (Statistical package). Through the application of descriptive statistical data analysis include (Frequencies, Percentage, Mean and Standard Deviation) and Inferential statistical data analysis include Chi-Square test for testing the different among several observed frequencies and their expected. The criteria of probability levels were used to determine the significance of the statistical test as following: Highly Significance (HS) at $(\mathrm{P} \leq 0.01)$, Significant $(\mathrm{S})$ at $(\mathrm{P} \leq 0.05)$ and NonSignificant (NS) at $(\mathrm{P}>0.05)$.

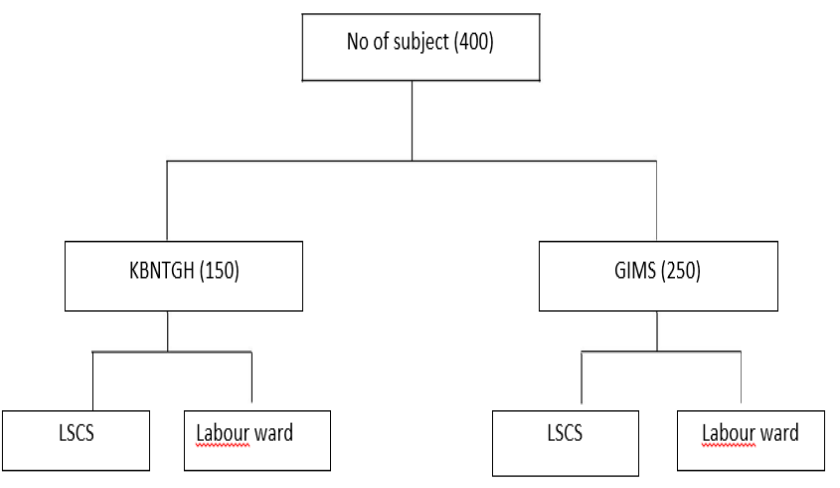

Figure 1: Consort Diagram.

\section{Results}

[Table 2] shows that the highest percentage $(47.8 \%)$ of study sample was at age group (18-21) years, (49 \%) was graduated from primary school and less. The highest percentage $(63 \%)$ of study sample was lower middle socioeconomic status.

Table (3) shows $79.4 \%$ of normal delivery whereas $77.8 \%$ of LSCS started breastfeeding in less than 24 hrs. Average latch score of $7(20 \%)$ in normal delivery and latch score of $4(23.6 \%)$ in LSCS. The chi-square statistic is 9.5104 . The pvalue is .049535 . The result is significant at $\mathrm{p}<.05$. Table (4) shows average latch score of $4(28.1 \%$ ) in primipara and score of 8 (30.5) in multipara. The chi-square statistic is 76.9858. The $\mathrm{p}$-value is $<.00001$. The result is significant at $\mathrm{p}<.05$

Table (5) shows that the highest percentage (91\%) of study 
sample initiate their breastfeeding during 24 hours. (17.3\%) were continued breastfeeding for 2 years.

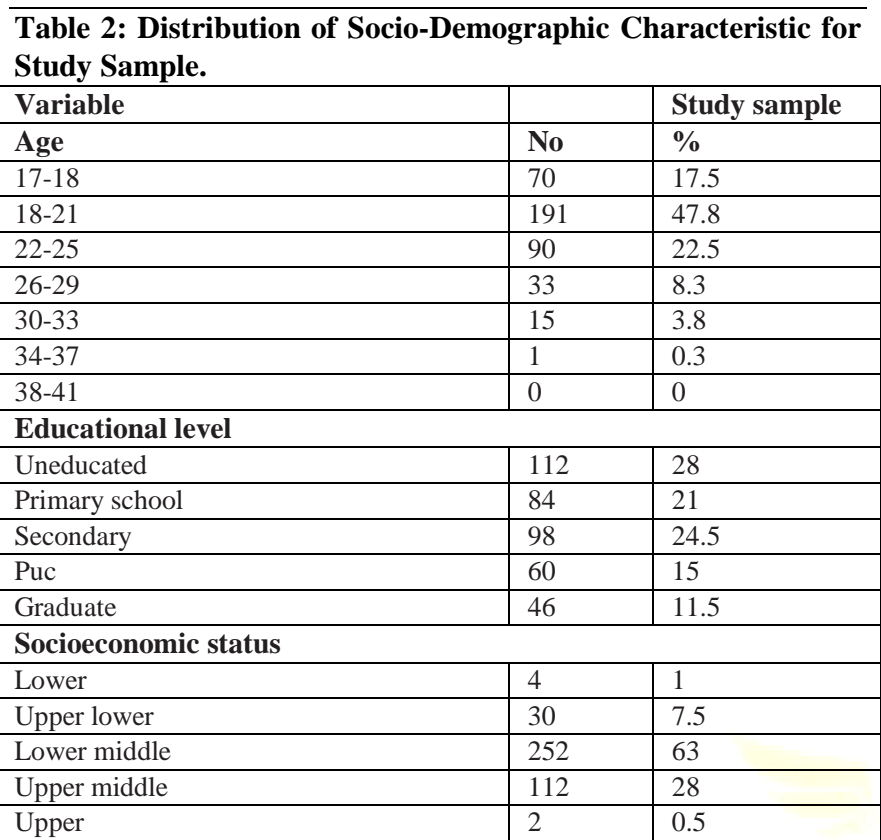

Table 3: breastfeeding assessment among normal and LSCS group

\begin{tabular}{|c|c|c|}
\hline & Nvd & Lscs \\
\hline Breastfeeding $<1 \mathrm{hr}$ & $60(15)$ & $4(1)$ \\
\hline Breastfed at $<24 \mathrm{hrs}$ & $139(79.4)$ & $175(77.8)$ \\
\hline Breastfed at day $>24 \mathrm{hr}$ & $36(20.6$ & $50(22.2)$ \\
\hline \multicolumn{3}{|l|}{ Latch score } \\
\hline 1 & $3(1.7)$ & $1(0.4)$ \\
\hline 2 & $2(1.1)$ & $7(3.1)$ \\
\hline 3 & $26(14.9)$ & $24(10.7)$ \\
\hline 4 & $25(14.3)$ & $53(23.6)$ \\
\hline 5 & $18(10.3)$ & $19(8.4)$ \\
\hline 6 & $18(10.3)$ & $26(11.6)$ \\
\hline 7 & $35(20)$ & $27(12)$ \\
\hline 8 & $29(16.6)$ & $43(19.1)$ \\
\hline 9 & $17(9.7)$ & $21(9.3)$ \\
\hline 10 & $2(1.1)$ & $4(1.8)$ \\
\hline
\end{tabular}

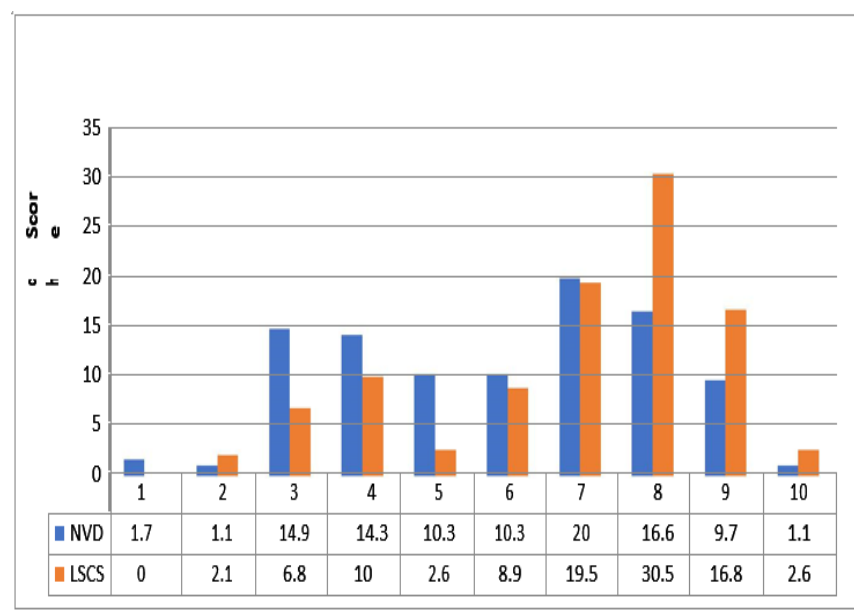

Figure 2: Latch score in NVD and LSCS
Table 4: breastfeeding assessment among primi and multipara

\begin{tabular}{|l|l|l|}
\hline Latch score & Primi & Multi \\
\hline 1 & $4(1.9)$ & $0(0)$ \\
\hline 2 & $5(2.4)$ & $4(2.1)$ \\
\hline 3 & $37(17.6)$ & $13(6.8)$ \\
\hline 4 & $59(28.1)$ & $19(10)$ \\
\hline 5 & $32(15.2)$ & $5(2.6)$ \\
\hline 6 & $27(12.9)$ & $17(8.9)$ \\
\hline 7 & $25(11.9)$ & $37(19.5)$ \\
\hline 8 & $14(6.7)$ & $58(30.5)$ \\
\hline 9 & $6(2.9)$ & $32(16.8)$ \\
\hline 10 & $1(0.5)$ & $5(2.6)$ \\
\hline
\end{tabular}

Table 5: Distribution of Previous Breastfeeding among Study Sample.

\begin{tabular}{|l|l|l|}
\hline \multicolumn{3}{|c|}{ Previous initiation of breastfeeding } \\
\hline & No & \% \\
\hline During 24 hrs & 364 & 91 \\
\hline After 24 hrs & 36 & 9 \\
\hline \multicolumn{3}{|c|}{ Previous duration of breastfeeding } \\
\hline None & 5 & 1.3 \\
\hline $1 \mathrm{yr}$ & 33 & 8.3 \\
\hline $1 \& 1 / 2 \mathrm{Yr}$ & 55 & 13.8 \\
\hline $2 \mathrm{yr}$ & 69 & 17.3 \\
\hline $3 \mathrm{yr}$ & 25 & 6.3 \\
\hline $4 \mathrm{yr}$ & 3 & 0.8 \\
\hline \multicolumn{3}{|c|}{ Type of previous delivery } \\
\hline $\mathrm{Nvd}$ & 98 & 24.5 \\
\hline Lscs & 92 & 23 \\
\hline
\end{tabular}

\section{Discussion}

Breastfeeding has multiple benefits for both the baby and the mother. Keys to successful breastfeeding include maternal-infant skin to skin (STS) contact soon after birth, initiation within first hour of birth, limiting maternal-infant separation and frequent on demand feeds. ${ }^{[7]}$ In addition to the benefits of breastmilk, putting the baby on breast also confers the other benefits of early skin to skin contact. ${ }^{\left[{ }^{8]}\right.}$ The experience of cesarean birth can be stressful to a mother who is unable to watch her baby enter the world. ${ }^{[9]}$ Providing her the opportunity to hold and feed the baby soon after birth can give a sense of empowerment and control. Parenting skills are enhanced, as the mother holds and feeds the baby herself and in turn, the neurodevelopment of the baby is better. The present study corroborates the findings of others that show that putting the babies on mother's breast for skin to skin contact/feeding during cesarean section is feasible. ${ }^{[10]}$

Immediate to early skin to skin contact of newborn with mother is recommended in all deliveries, including caesarean section. ${ }^{[1,12]}$ skin to skin contact culminates to early initiation of breastfeeding (EIBF)by one hour after birth and leads to successful initiationof lactation. ${ }^{[13,8]} \mathrm{EIBF}$ reduces neonatal and infant mortality rate by achieving higher rates of sustained breast feeding. ${ }^{[13,14]}$

As an assessment tool, the LATCH system focuses on specific criteria that include the key components of 
breastfeeding. As a communication tool, LATCH scores identify areas of needed intervention. The nursing staff can then assign priorities for providing breastfeeding assistance, focusing first on those mothers and infants with lower LATCH scores. As a tool for teaching new mothers to breastfeed, the five assessment areas of LATCH outline an information base that is consistent with current research on the principles of effective breastfeeding. ${ }^{[6]}$

The level of education plays a large role in influencing a women to exclusive breastfeed their children. It has been found that mothers with a higher education level tend to initiate breastfeeding more often, and also tend to breastfeed their child for a longer period of time than do their less educated counterparts. ${ }^{[15]}$

Parity also strongly influences breastfeeding success. Multipara have shorter labour, less need for delivery analgesia, earlier lactation onset (lactogenesis II), and, possibly, previous experience with breastfeeding. All these factors can positively influence breastfeeding initiation and duration. ${ }^{[16]}$

Fish bone analysis as given in [Figure 3], revealed that the reason for exclusively breastfeeding to the neonates during the hospital stay is not assured were related to people, place, policy, process and environment. Lack of knowledge, sensitization of health care provider and lack of support for the mother were few of the vital reason limiting the breastfeeding practice.

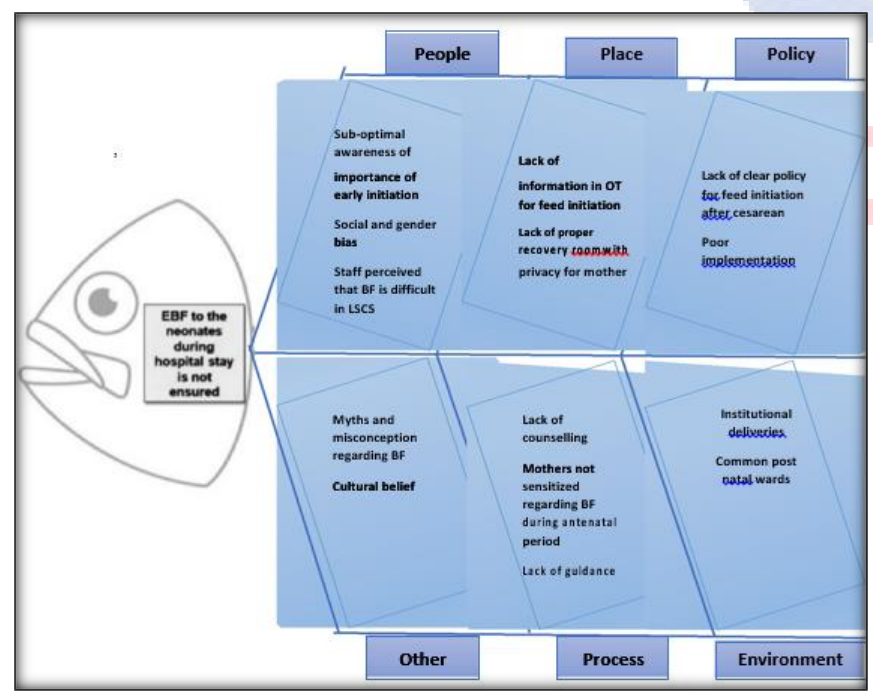

Figure 3: Fish bone analysis.

\section{Conclusion}

1. Neonatal and infant deaths can be decreased to significant level if breast feeding is initiated within 1 hour

2. LATCH score is excellent tool for caregivers at all level in hospital.

3. Early initiation will help to sustained and maintain breastfeeding till 6 months of age and avoid top feeding by the mother.

\section{Acknowledgements}

Mr Nayeem Assistant Nursing Superintendent and nursing staff of labour room-operation theatre and labour room for their cooperation and support. We are also thankful to Dr Siddaling Chengty, Dr Vinod Uplaonkar, Department of Pediatrics KBNTGH; Dr Sandeep,

Department of Pediatrics GIMS; Dr Rajashree Palade, Department of Obstetrics and Gynecology, KBNTGH; Dr Nirmala Rampure, Department of Obstetrics and Gynecology, GIMS; Dr Tejashwini, Department of Anesthesia, KBNTGH for their guidance and valuable inputs during the study

\section{References}

1. National Family Health Survey - 4. 2017. Available from: http://rchiips.org/nfhs/pdf/NFHS4/India.pdf. Accessed October 15, 2017.

2. Edmond K, Newton S, Hurt L, Shannon CS, Kirkwood BR, Mazumder $\mathrm{S}$, et al. Timing of initiation, patterns of breastfeeding, and infant survival: Prospective analysis of pooled data from three randomised trials. Lancet Glob Heal. 2016;4:e266-75.

3. WorldHealth Organization. Breastfeeding. http://www.who.int/elena/titles/early_breastfeeding/en/

4. Patel A, Banerjee A, Kaletwad A. Factors associated with prelacteal feeding and timely initiation of breastfeeding in hospital-delivered infants in India. J Hum Lact. 2013;29:572-8.

5. Rowe-Murray HJ, Fisher JRW. Baby Friendly Hospital practices: Cesarean section is a persistent barrier to early initiation of breastfeeding. Birth. 2002;29:124-31.

6. Jensen D, Wallace L, Kalsay P. Latch: A breastfeeding charting system and documentation tool. Jognn principle and practice 1994; 23(1):2829.

7. Mikiel-Kostyra K, Mazur J, Wojdan-Godek E. Factors affecting exclusive breastfeeding in Poland: cross-sectional survey of populationbased samples. Social Prev Med. 2005;50:52-9

8. Moore ER, Anderson GC, Bergman N, Dowswell T. Early skin-to-skin contact for mothers and their healthy newborn infants. Cochrane Database Syst Rev. 2007;3:CD350019.

9. Baby-friendly Hospital Initiative: Revised, Updated and Expanded for integrated Care 2009. Available from: https://www.unicef.org/nutrition/files/BFHI section_2_2009_eng.pdf. Accessed October 14, 2017.

10. Hung KJ, Berg O. Early skin-to-skin after cesarean to improve breastfeeding. Am J MaternNurs. 2011;36: 318-24.

11. Baby Friendly Hospital Initiative 2009 update section-1Background and implementation. UNICEF Available from:www.who.int/nutrition/publications/infantfeeding/bfhi_trainingco urse_s1/en/.

12. Tiwari S, Bharadwa K, Yadav D, Malik S, Gangal P,Bsanapurmath CR. Infant andYoung Child FeedingGuidelines, 2016. Indian Pediatr. 2016;53:703-13.

13. Suzuki S. Effect of early skin-to-skin contact on breast-feeding. J ObstetGynaecol. 2013; 33:695-6.

14. Moore ER, Bergman N, Anderson GC, Medley N. Earlyskin-to-skin contact for mothers and their healthy newborninfants. Cochrane Database Syst Rev. 2016;11:CD003519

15. Shelton M. \& Qi Wang M.: Demographic factors associated with the duration of mothers' breastfeeding, American Journal of Health Studies, 1997, 13: 195-200. 
16. Dewey KG, Nommsen-Rivers LA, Heinig MJ, et al. Risk factors for

and excess neonatal weight loss. Pediatrics 2003;112:607-619. suboptimal infant breastfeeding behavior, delayed onset of lactation,

Copyright: () the author(s), 2019. It is an open-access article distributed under the terms of the Creative Commons Attribution License (CC BY 4.0), which permits authors to retain ownership of the copyright for their content, and allow anyone to download, reuse, reprint, modify, distribute and/or copy the content as long as the original authors and source are cited.

How to cite this article: Sandeep H, Uplaonkar V. Adherence and Early Initiation of Breastfeeding in Institutional Deliveries - Prospective Observational Cohort Study. Asian J. Clin. Pediatr. Neonatol.2019;7(1):22-26.

DOI: dx.doi.org/10.21276/ajcpn.2019.7.1.6

Source of Support: Nil, Conflict of Interest: None declared. 